\title{
SEKTOR EKONOMI UNGGULAN KABUPATEN LOMBOK TENGAH
}

\author{
Muhammad Zainuri \\ Badan Pusat Statistik Provinsi Nusa Tenggara Barat \\ zainuri@bps.go.id
}

Diterima: Oktober 2020; Disetujui: Maret 2021

\begin{abstract}
Lombok Tengah Regency has the potential to accelerate economic growth in the future along with the presence of the Mandalika Special Economic Zone (SEZ). This study aims to determine the leading economic sectors of Lombok Tengah Regency and explain the relationship between these leading economic sectors and the tourism activities. Based on the overlay analysis that combines shift share analysis and location quotient analysis, it is found that of the 17 (seventeen) existing economic sectors, all of them are included in the leading sector as many as 9 (nine) sectors and potential sector categories as many as 8 (eight) sectors. The transportation and warehousing sector and the accommodation and food and beverage provision sector which are closely related to tourism activities are not yet among the leading sectors, so they need to be improved in the future. Leading economic sectors such as agriculture, forestry and fisheries sector; manufacturing industry sector; and the services sector can take advantage of the presence of the Mandalika Special Economic Zone (SEZ) to increase demand. Further research can use Input Output Table Analysis to determine the interrelationship between economic sectors and to know the impact of improving an economic sector on the performance of the economy in general.
\end{abstract}

Keyword: leading economic sector, shift share, locational quotient, overlay analysis.

Abstraksi. Kabupaten Lombok Tengah berpotensi melakukan akselerasi pertumbuhan ekonomi di masa mendatang seiring dengan hadirnya Kawasan Ekonomi Khusus (KEK) Mandalika. Penelitian ini bertujuan untuk mengetahui sektor ekonomi unggulan yang dimiliki Kabupaten Lombok Tengah dan membahas keterkaitan sektor ekonomi unggulan tersebut dengan kegiatan pariwisata. Berdasarkan analisis overlay yang memadukan analisis shift share dan analisis location quotient, diperoleh hasil bahwa dari 17 (tujuh belas) sektor ekonomi yang ada, seluruhnya termasuk dalam kategori sektor unggulan sebanyak 9 (sembilan) sektor dan kategori sektor potensial sebanyak 8 (delapan) sektor. Sektor transportasi dan pergudangan serta sektor penyediaan akomodasi dan makan minum yang terkait erat dengan kegiatan pariwisata belum termasuk sektor unggulan sehingga perlu ditingkatkan di masa mendatang. Sektor ekonomi unggulan seperti sektor pertanian, kehutanan, dan perikanan; sektor industri pengolahan; dan sektor jasa-jasa dapat memanfaatkan hadirnya Kawasan Ekonomi Khusus (KEK) Mandalika untuk menambah permintaan (demand). Penelitian selanjutnya dapat mengunakan Analisis Tabel Input Output untuk mengetahui keterkaitan antar sektor ekonomi dan mengetahui dampak dari peningkatan suatu sektor ekonomi terhadap kinerja perekonomian secara umum.

Kata kunci: sektor ekonomi unggulan, shift share, locational quotient, analisis overlay.

\section{PENDAHULUAN}

Kabupaten Lombok Tengah merupakan salah satu kabupaten di Provinsi Nusa Tenggara Barat (NTB). Kabupaten dengan luas $1.208,93 \mathrm{~km}^{2}$ tersebut memiliki penduduk yang mencapai 955,4 ribu jiwa pada tahun 2019. Nilai Produk Domestik Regional Bruto (PDRB) Kabupaten Lombok Tengah telah mencapai 17,88 triliun rupiah (atas dasar harga berlaku) 
pada tahun 2019. Dengan nilai PDRB tersebut, PDRB per kapita penduduk Kabupaten Lombok Tengah mencapai 18,7 juta rupiah per tahun.

Pembangunan Daerah yang berjalan di Kabupaten Lombok Tengah menunjukkan perkembangan yang positif. Pada periode 2015-2019, Tingkat Pengangguran Terbuka (TPT) di kabupaten tersebut turun dari 7,42 persen menjadi 2,44 persen. Dari aspek kemiskinan, pada periode 2015-2019 terjadi penurunan tingkat kemiskinan dari 16,26 persen menjadi 13,63 persen. Dilihat dari aspek pembangunan manusia, Kabupaten Lombok Tengah berhasil meningkatkan Indeks Pembangunan Manusia (IPM) dari angka 62,74 pada tahun 2015 menjadi 66,36 pada tahun 2019.

Pencapaian pembangunan daerah yang diraih Kabupaten Lombok Tengah ditopang oleh pertumbuhan ekonomi yang relatif stabil pada periode 2015-2019. Badan Pusat Statistik (BPS) (2020b) mencatat pertumbuhan ekonomi Kabupaten Lombok Tengah pada tahun 2015 mencapai 5,60 persen. Pada dua tahun berikutnya pertumbuhan ekonomi mencapai 5,65 persen (tahun 2016) dan 6,43 persen (tahun 2017). Musibah gempa yang menimpa Provinsi Nusa Tenggara Barat pada tahun 2018 memberi dampak pada perekonomian Kabupaten Lombok Tengah. Pada tahun 2018, pertumbuhan ekonomi Kabupaten Lombok Tengah melambat menjadi 3,16 persen. Akhirnya pada tahun 2019, pertumbuhan ekonomi kembali mengalami percepatan dengan laju pertumbuhan 4,07 persen.

Kabupaten Lombok Tengah masih membutuhkan akselerasi pertumbuhan ekonomi di waktu mendatang. Tingkat kemiskinan Kabupaten Lombok Tengah yang masih di atas 10 persen pada tahun 2019. Selain itu, IPM Kabupaten Lombok
Tengah belum masuk kategori tinggi pada tahun 2019. Salah satu peluang yang dapat dimanfaatkan Kabupaten Lombok Tengah untuk melakukan akselerasi pertumbuhan ekonomi adalah keberadaan Kawasan Ekonomi Khusus (KEK) Mandalika yang berlokasi di pesisir selatan Kabupaten Lombok Tengah.

Menurut Dewan Nasional Kawasan Ekonomi Khusus, KEK Mandalika merupakan KEK yang paling menarik para investor saat ini dan diharapkan menjadi destinasi wisata kelas dunia. KEK Mandalika diproyeksikan menarik investasi sebesar 40 triliun rupiah dan diproyeksikan dapat menyerap sebanyak 587.000 tenaga kerja pada tahun 2025 (DN KEK RI, n.d.). Selain itu, KEK Mandalika akan menjadi tuan rumah Federation Internationale de Motocyclisme (FIM) MotoGP World Championship dan Motul FIM Superbike World Championship mulai tahun 2021 (ITDC, 2019).

Menurut Darmastuti, et.al (2018), KEK merupakan salah satu pendorong pembangunan ekonomi di banyak negara berkembang. Salah satu contoh sukses KEK terjadi di Cina. Kemampuan KEK dalam menarik investor dan mendorong pertumbuhan ekonomi di daerah yang berdekatan hingga pada akhirnya membawa kesuksesan pada ekonomi Cina secara keseluruhan.

KEK Mandalika merupakan KEK pariwisata yang berpotensi menjadi magnet yang kuat bagi kedatangan wisatawan baik domestik maupun mancanegara. Kemajuan aktivitas pariwisata di Lombok Tengah akan mendorong pertumbuhan berbagai sektor eknomi karena aktivitas pariwisata memiliki keterkaitan dengan berbagai sektor ekonomi seperti sektor transportasi, penyediaan akomodasi dan makan minum, industri kreatif dan jasa-jasa. Pada level 
provinsi, pariwisata berpotensi menjadi lokomotif baru ekonomi Provinsi NTB (Islamy, 2019).

Optimalisasi manfaat kehadiran KEK Mandalika bagi kemajuan ekonomi daerah Lombok Tengah memerlukan orientasi pemanfaatan KEK yang tepat. Menurut Narula dan Zhan (2019), pengembangan KEK di masa mendatang harus mengurangi ketergantungan pada keuntungan lokasi (locational advantage) yang umum dan lebih menekankan pada keuntungan lokasi yang khusus.

Untuk memperoleh pemanfaatan KEK yang lebih ditekankan pada keuntungan lokasi yang khusus, diperlukan informasi terkait sektor ekonomi unggulan yang dimiliki oleh Kabupaten Lombok Tengah. Penelitian ini bertujuan untuk mengetahui sektor ekonomi unggulan yang dimiliki Kabupaten Lombok Tengah dan membahas keterkaitan sektor ekonomi unggulan tersebut dengan kegiatan pariwisata.

\section{METODE PENELITIAN}

Metode penelitian yang digunakan adalah penelitian kuantitatif. Metode yang digunakan dalam menentukan sektor ekonomi unggulan di Kabupaten Lombok Tengah adalah Analisis Shift Share, Analisis Locational Quotients (LQ), dan Analisis Overlay (Arsyad, 2016).

\section{Analisis Shift Share}

Analisis shift share pada dasarnya menggambarkan kinerja dan produktivitas sektor-sektor dalam perekonomian suatu wilayah dengan membandingkannya dengan kinerja sektor-sektor di wilayah yang lebih besar (provinsi/nasional). Analisis ini membandingkan laju petumbuhan sektor-sektor ekonomi regional (kota/kabupaten) dengan laju pertumbuhan perekonomian yang lebih tinggi tingkatannya (Provinsi). Dengan menggunakan Analisis shift-share dapat diketahui perubahan struktur perekonomian selama periode pengamatan tertentu. Data yang digunakan adalah PDRB sektoral (Arsyad, 2016).

Data PDRB sektoral pada analisis shift share merupakan variabel yang menggambarkan ketersediaan lapangan kerja (employment). Dalam Tarigan (2006), pertambahan lapangan kerja (employment) regional total $\left(\Delta E_{r}\right)$ pada periode tertentu dapat dibedakan menjadi komponen shift dan komponen share. Komponen share sering disebut komponen national share, yaitu banyaknya pertambahan lapangan kerja regional seandainya proporsi perubahannya sama dengan laju pertambahan nasional pada priode studi. Istilah nasional menunjukkan wilayah di atasnya.

Komponen shift adalah penyimpangan (deviation) dari national share dalam pertumbuhan lapangan kerja regional. Penyimpangan ini bernilai positif di daerah yang tumbuh lebih cepat dan bernilai negatif di daerah yang tumbuh lebih lambat/merosot dibandingkan pertumbuhan nasional. Besarnya penyimpangan disebut shift regional netto. Di setiap daerah, shift regional netto dibagi menjadi proportional shift component dan different shift component.

Proportional shift component disebut juga industrial mix component, mengukur besarnya shift regional netto yang diakibatkan oleh komposisi sektor-sektor ekonomi di daerah yang bersangkutan. Komponen ini akan bernilai positif di daerah yang berspesialisasi dalam sektor ekonomi yang pada level nasional tumbuh cepat dan akan bernilai negatif di daerah yang berspesialisasi dalam sektor ekonomi yang pada level nasional tumbuh dengan lambat atau bahkan sedang merosot. 
Differential shift disebut juga locational/ regional component, mengukur besarnya shift regional netto yang diakibatkan oleh sektor-sektor ekonomi tertentu yang tumbuh lebih cepat atau lebih lambat di daerah yang bersangkutan dibandingkan tingkat nasional (diatasnya). Hal ini disebabkan oleh faktor-faktor intern di suatu daerah (intern locational factors). Daerah yang memiliki keuntungan lokasional seperti sumberdaya berlimpah/ efisien akan memiliki different shift component yang positif, sedangkan daerah yang secara lokasional tidak menguntungkan akan mempunyai nilai komponen yang negatif.

Pertambahan lapangan kerja (employment) regional sektor- $i\left(\Delta E_{r, i}\right)$ dirumuskan sebagai:

$$
\Delta E_{r, i}=E_{r, i, t}-E_{r, i, 0}
$$

Keterangan:

$E_{r, i, t}$ : jumlah lapangan kerja regional sektor- $i$ pada tahun akhir penelitian $(t)$.

$E_{r, i, 0}$ : jumlah lapangan kerja regional sektor- $i$ pada tahun awal penelitian $(0)$.

Pertambahan lapangan kerja (employment) regional sektor- $i \quad\left(\Delta E_{r, i}\right)$ tersebut dapat dirinci menurut pengaruh dari national share (Ns), proportional shift $(P)$, dan differential shift $(D)$, atau:

$\Delta E_{r, i}=N s_{i}+P_{r, i}+D_{r, i}$

Keterangan:

$N s_{i}$ adalah nilai peranan national share terhadap sektor- $i$

$P_{r, i}$ adalah nilai komponen proportional shift pada sektor- $i$

$D_{r, i}$ adalah nilai komponen differential shift pada sektor- $i$

Rumus penghitungan masing-masing komponen dalam analisis shift share adalah:
National Share (Ns)

$$
N s_{i}=E_{r, i, 0}\left(\frac{E_{N, t}}{E_{N, 0}}-1\right)
$$

Proportional Shift $(P)$

$P_{r, i}=E_{r, i, 0}\left\{\left(\frac{E_{N, i, t}}{E_{N, i, 0}}-1\right)-\left(\frac{E_{N, t}}{E_{N, 0}}-1\right)\right\}$

\section{Differential Shift $(D)$}

$D_{r, i}=E_{r, i, 0}\left\{\left(\frac{E_{r, i, t}}{E_{r, i, 0}}-1\right)-\left(\frac{E_{N, i, t}}{E_{N, i, 0}}-1\right)\right\}$

Keterangan:

$E_{r, i, 0}$ : jumlah lapangan kerja regional sektor- $i$ pada tahun awal penelitian $(0)$.

$E_{r, i, t}$ : jumlah lapangan kerja regional sektor- $i$ pada tahun akhir penelitian $(t)$.

$E_{N, i, 0}$ : jumlah lapangan kerja nasional sektor- $i$ pada tahun awal penelitian $(0)$.

$E_{N, i, t}$ : jumlah lapangan kerja nasional sektor-i pada tahun akhir penelitian $(t)$.

$E_{N, 0}$ : jumlah lapangan kerja nasional total pada tahun awal penelitian $(0)$.

$E_{N, t}$ : jumlah lapangan kerja nasional total pada tahun akhir penelitian $(t)$.

\section{Location Quotient}

Location quotient ( $L Q)$ merupakan suatu pendekatan tidak langsung yang digunakan untuk mengukur kinerja basis ekonomi suatu daerah. Artinya bahwa analisis ini digunakan untuk melakukan pengujian sektor-sektor ekonomi yang termasuk dalam kategori sektor unggulan. $L Q$ digunakan untuk mengukur konsentrasi dari suatu sektor ekonomi dalam suatu daerah dengan cara membandingkan peranannya dalam perekonomian suatu daerah dengan peranan sektor ekonomi sejenis dalam perekonomian regional atau nasional. Analisis ini membantu dalam menentukan kapasitas ekspor perekonomian daerah dan derajat self-sufficiency suatu sektor. LQ digunakan untuk memperluas analisis shiftshare (Arsyad, 2016). 
Menurut Tarigan (2006), ada banyak variabel yang bisa diperbandingkan dalam LQ, tetapi yang umum adalah nilai tambah (tingkat pendapatan) atau PDRB dan jumlah lapangan kerja. Pada penelitian ini, variabel yang digunakan adalah nilai tambah bruto (tingkat pendapatan), sehingga rumus penghitungan LQ yang digunakan adalah:

$$
L Q_{i, t}=\frac{V_{r, i, t} \cdot V_{N, t}}{V_{r, t} \cdot V_{N, i, t}}
$$

Keterangan:

$L Q_{i, t}$ : nilai LQ sektor ke-i pada tahun tertentu $(t)$

$V_{r, i, t}:$ Nilai tambah regional sektor- $i$ pada tahun tertentu $(t)$

$V_{r, t}:$ Total nilai tambah regional atau PDRB kabupaten tahun tertentu $(t)$

$V_{N, i, t}$ : Nilai tambah nasional sektor- $i$ pada tahun tertentu $(t)$

$V_{N, t}$ : Total nilai tambah nasional atau PDRB provinsi tahun tertentu $(t)$

Menurut Arsyad (2016), kriteria penggolongan LQ yaitu 1) $\mathbf{L Q}=\mathbf{1}$, berarti produk domestik yang dimiliki daerah tersebut habis dikonsumsi oleh daerah tersebut sendiri. Penduduk suatu daerah dapat memenuhi kebutuhannya akan suatu barang dengan hasil produksi barang tersebut di daerah sendiri. 2) $\mathbf{L Q}>\mathbf{1}$, berarti sektor yang ada di daerah tersebut merupakan sektor basis yang mampu mengekspor hasil produksinya ke daerah lain. 3) $\mathbf{L Q}<\mathbf{1}$, berarti sektor yang ada di daerah tersebut bukan merupakan sektor basis dan cenderung untuk mengimpor dari daerah lain.

\section{Analisis Overlay}

Metode ini digunakan untuk menentukan sektor unggulan dengan menggabungkan hasil dari metode analisis shift-share dan location quotient $(L Q)$. Tujuan dari analisis overlay ini adalah untuk melihat deskripsi kegiatan ekonomi yang potensial berdasarkan kriteria kontribusi (analisis location quotient) dan kriteria pertumbuhan (analisis shift-share).

Dalam analisis overlay ini akan didapatkan 4 (empat) kemungkinan, yaitu 1) Jika pertumbuhan (+) dan kontribusi (+), maka sektor tersebut cukup dominan sehingga harus mendapatkan prioritas dalam pembangunan. 2) Jika pertumbuhan (+) dan kontribusi (-), maka sektor tersebut sedang mengalami perkembangan sehingga perlu mendapatkan perhatian untuk ditingkatkan kontribusinya dalam pembentukan PDRB. 3) Jika pertumbuhan (-) dan kontribusi (+), maka sektor tersebut sedang mengalami penurunan sehingga perlu dipacu pertumbuhannya. 4) Jika pertumbuhan (-) dan kontribusi (-), maka sektor tersebut tidak potensial sehingga tidak layak untuk dikembangkan (Arsyad, 2016).

\section{Data yang Digunakan}

Data yang digunakan pada penelitian ini adalah data sekunder yang bersumber dari Badan Pusat Statistik (BPS) berupa data PDRB. Mengacu kepada konsep daerah analisis (regional) dan daerah acuan (nasional) atau wilayah di atasnya, pada penelitian ini yang menjadi wilayah regional adalah Kabupaten Lombok Tengah dan yang menjadi wilayah nasional adalah Provinsi Nusa Tenggara Barat.

Periode analisis data pada penelitian ini mencakup tahun 2015 sampai dengan tahun 2019. Adapun data PDRB yang digunakan adalah Atas Dasar Harga Konstan (ADHK) tahun 2010. Oleh karena itu, data yang digunakan pada penelitian ini adalah PDRB ADHK Kabupaten Lombok Tengah Tahun 2015-2019 dan PDRB ADHK Provinsi NTB Tahun 2015-2019. 
HASIL DAN PEMBAHASAN

\section{Analisis Shift Share}

Hasil penghitungan shift share Kabupaten Lombok Tengah Tahun 20152019 dapat dilihat pada Tabel 1. Sektor unggulan adalah sektor yang memiliki shift regional netto bernilai positif. Berdasarkan Tabel 1 dapat diketahui bahwa terdapat 16 (enam belas) sektor ekonomi memenuhi kriteria sebagai sektor unggulan karena memiliki pertumbuhan yang progresif (maju). Dengan kata lain, hampir seluruh sektor ekonomi menunjukkan kondisi pertumbuhan yang menggembirakan.
Hanya 1 (satu) sektor ekonomi yang memiliki shift regional netto negatif atau tumbuh lamban, yaitu Sektor transportasi dan pergudangan. Kabupaten Lombok Tengah memiliki nilai tambah ekonomi subsektor angkutan udara terbesar di Provinsi NTB karena Bandara Internasional Lombok terletak di Kabupaten Lombok Tengah. Musibah gempa pada tahun 2018 berdampak pada menurunnya jumlah wisatawan yang sebagian besar menggunakan angkutan udara. Pada tahun 2019, subsektor angkutan udara masih dalam tahap pemulihan.

Tabel 1.

Hasil Perhitungan Nilai Shift Share Kabupaten Lombok Tengah Tahun 2015-2019 (juta rupiah)

\begin{tabular}{|c|c|c|c|c|c|}
\hline \multirow[b]{2}{*}{ Sektor Ekonomi } & \multicolumn{3}{|c|}{ Komponen } & \multirow{2}{*}{$\begin{array}{c}\text { Shift } \\
\text { Regional } \\
\text { Netto } \\
\left(\mathrm{P}_{\mathrm{r}, \mathrm{i}}+\mathrm{D}_{\mathrm{r}, \mathrm{i}}\right)\end{array}$} & \multirow[b]{2}{*}{$\begin{array}{l}\text { Pertambahan } \\
\text { Lapangan } \\
\operatorname{Kerja}\left(\Delta E_{r, i}\right)\end{array}$} \\
\hline & $\begin{array}{l}\text { National } \\
\text { Share } \\
\left(\mathrm{Ns}_{\mathrm{i}}\right)\end{array}$ & $\begin{array}{l}\text { Proportional } \\
\quad \text { Shift }\left(\mathrm{P}_{\mathrm{r}, \mathrm{i}}\right)\end{array}$ & $\begin{array}{l}\text { Different } \\
\text { Shift }\left(\mathrm{D}_{\mathrm{r}, \mathrm{i}}\right)\end{array}$ & & \\
\hline $\begin{array}{l}\text { Pertanian, Kehutanan, dan } \\
\text { Perikanan }\end{array}$ & 143.532 & 233.095 & 2.631 & 235.726 & 379.258 \\
\hline $\begin{array}{l}\text { Pertambangan dan } \\
\text { Penggalian }\end{array}$ & 22.542 & $(209.349)$ & 358.717 & 149.368 & 171.910 \\
\hline Industri Pengolahan & 31.542 & 75.241 & $(25.607)$ & 49.633 & 81.175 \\
\hline Pengadaan Listrik dan Gas & 391 & 1.912 & (185) & 1.726 & 2.118 \\
\hline $\begin{array}{l}\text { Pengadaan Air, Pengelolaan } \\
\text { Sampah, Limbah dan Daur } \\
\text { Ulang }\end{array}$ & 673 & 552 & (59) & 493 & 1.166 \\
\hline Konstruksi & 66.556 & 370.739 & 84.092 & 454.831 & 521.387 \\
\hline $\begin{array}{l}\text { Perdagangan Besar dan } \\
\text { Eceran; Reparasi Mobil dan } \\
\text { Sepeda Motor }\end{array}$ & 57.470 & 287.233 & $(2.553)$ & 284.680 & 342.151 \\
\hline $\begin{array}{l}\text { Transportasi dan } \\
\text { Pergudangan }\end{array}$ & 92.567 & 192.062 & (196.660) & $(4.598)$ & 87.969 \\
\hline $\begin{array}{l}\text { Penyediaan Akomodasi dan } \\
\text { Makan Minum }\end{array}$ & 5.561 & 7.814 & 11.141 & 18.954 & 24.516 \\
\hline Informasi dan Komunikasi & 9.371 & 43.846 & $(1.429)$ & 42.418 & 51.789 \\
\hline Jasa Keuangan dan Asuransi & 10.336 & 56.436 & (1.317) & 55.119 & 65.454 \\
\hline Real Estate & 18.335 & 67.886 & 3.024 & 70.910 & 89.245 \\
\hline Jasa Perusahaan & 772 & 2.915 & (90) & 2.825 & 3.597 \\
\hline $\begin{array}{l}\text { Administrasi Pemerintahan, } \\
\text { Pertahanan dan Jaminan } \\
\text { Sosial Wajib }\end{array}$ & 29.111 & 34.212 & (11.317) & 22.894 & 52.005 \\
\hline Jasa Pendidikan & 23.495 & 98.780 & $(1.476)$ & 97.304 & 120.799 \\
\hline $\begin{array}{l}\text { Jasa Kesehatan dan Kegiatan } \\
\text { Sosial }\end{array}$ & 13.361 & 63.078 & $(2.539)$ & 60.539 & 73.901 \\
\hline Jasa lainnya & 12.223 & 50.767 & $(1.853)$ & 48.914 & 61.136 \\
\hline
\end{tabular}

Sumber: Data diolah 
Nilai komponen national share menunjukkan nilai pertambahan lapangan kerja di Kabupaten Lombok Tengah yang disumbangkan oleh pertumbuhan ekonomi Provinsi NTB secara umum. Pada Tabel 1 terlihat bahwa pengaruh ekonomi Provinsi NTB terbesar pada sektor pertanian, kehutanan, dan perikanan dengan nilai $\mathrm{Ns}_{\mathrm{i}}$ sebesar 143,5 miliar rupiah.

Nilai komponen Proportional shift $\left(\mathrm{P}_{\mathrm{r}, \mathrm{i}}\right)$ menunjukkan pengaruh kemajuan teknologi dalam proses produksi suatu sektor ekonomi di Provinsi NTB terhadap pertambahan lapangan kerja di Kabupaten Lombok Tengah. Pada Tabel 1 terlihat bahwa sebanyak 16 (enam belas) sektor ekonomi memiliki nilai komponen $\mathrm{P}_{\mathrm{r}, \mathrm{i}}$ yang positif. Nilai $\mathrm{P}_{\mathrm{r}, \mathrm{i}}$ terbesar dimiliki sektor kontruksi sebesar 370,7 miliar rupiah.

Berdasarkan nilai $\mathrm{P}_{\mathrm{r}, \mathrm{i}}$ masing-masing sektor ekonomi, dapat diketahui bahwa kemajuan teknologi dalam proses produksi di Provinsi NTB telah berkontribusi positif bagi peningkatan lapangan kerja pada hampir seluruh sektor ekonomi di Kabupaten Lombok Tengah pada periode 2015-2019. Hanya 1 (satu) sektor ekonomi yang memiliki nilai komponen yang negatif yaitu sektor pertambangan dan penggalian. Sektor ekonomi tersebut pada level Provinsi NTB merupakan sektor ekonomi yang memiliki pertumbuhan yang kurang stabil akibat berfluktuasinya permintaan hasil produksi pertambangan bijih logam pada periode 2015-2019.

Nilai komponen Differential Shift $\left(\mathrm{D}_{\mathrm{r}, \mathrm{i}}\right)$ menunjukkan keunggulan kompetitif yang dimiliki Kabupaten Lombok Tengah dalam mendorong pertambangan lapangan kerja. Pada Tabel 1 terlihat bahwa terdapat 5 (lima) sektor ekonomi yang memiliki nilai $\mathrm{D}_{\mathrm{r}, \mathrm{i}}$ yang positif. Kelima sektor tersebut adalah sektor pertanian, kehutanan, dan perikanan; sektor pertambangan dan penggalian; sektor konstruksi; sektor penyediaan akomodasi dan makan minum; dan sektor real estate.

Dalam kaitannya dengan kegiatan pariwisata, Kabupaten Lombok Tengah memiliki keunggulan kompetitif pada sektor penyediaan akomodasi dan makan minum. Sektor tersebut merupakan sektor kunci dalam mendukung kegiatan pariwisata.

\section{Analisis Location Quotient}

Hasil penghitungan location quotient Kabupaten Lombok Tengah Tahun 20152019 dapat dilihat pada Tabel 2. Berdasarkan rata-rata angka indeks LQ masing-masing sektor ekonomi, diketahui bahwa terdapat 10 (sepuluh) sektor ekonomi yang termasuk sektor basis dengan nilai LQ > 1, yaitu: 1) Sektor Pertanian, Kehutanan, dan Perikanan, 2) Sektor Industri Pengolahan, 3) Sektor Pengadaan Air, Pengelolaan Sampah, Limbah dan Daur Ulang, 4) Sektor Konstruksi, 5) Sektor Tranportasi dan Pergudangan, 6) Sektor Real Estate, 7) Sektor Administrasi Pemerintahan, Pertahanan dan Jaminan Sosial Wajib, 8) Sektor Jasa Pendidikan, 9) Sektor Jasa Kesehatan dan Kegiatan Sosial, 10) Sektor Jasa Lainnya.

Sepuluh sektor basis tersebut memiliki kemampuan mengekspor barang dan jasa ataupun tenaga kerja ke tempat-tempat di luar batas perekonomian Kabupaten Lombok Tengah.

Nilai LQ terbesar dimiliki sektor transportasi dan pergudangan dengan nilai LQ sebesar 2,487. Sektor ekonomi tersebut merupakan sektor kunci dalam kegiatan pariwisata. Kabupaten Lombok Tengah memiliki subsektor angkutan udara dan subsektor angkutan darat untuk keperluan mobilitas wisatawan. Keberadaan Bandara Internasional di Kabupaten Lombok 
Tengah merupakan keuntungan tersendiri dari aspek ekonomi.

Tabel 2.

Hasil Perhitungan Indeks LQ Kabupaten Lombok Tengah Tahun 2015-2019

\begin{tabular}{|c|c|c|c|c|c|c|}
\hline \multirow{2}{*}{ Sektor Ekonomi } & \multicolumn{5}{|c|}{ Tahun } & \multirow{2}{*}{$\begin{array}{l}\text { Rata- } \\
\text { rata LQ }\end{array}$} \\
\hline & 2015 & 2016 & 2017 & 2018 & 2019 & \\
\hline Pertanian, Kehutanan, dan Perikanan & 1,257 & 1,255 & 1,179 & 1,096 & 1,097 & 1,177 \\
\hline Pertambangan dan Penggalian & 0,162 & 0,167 & 0,210 & 0,311 & 0,348 & 0,240 \\
\hline Industri Pengolahan & 1,389 & 1,361 & 1,265 & 1,171 & 1,167 & 1,271 \\
\hline Pengadaan Listrik dan Gas & 0,966 & 0,956 & 0,908 & 0,838 & 0,826 & 0,899 \\
\hline $\begin{array}{l}\text { Pengadaan Air, Pengelolaan Sampah, } \\
\text { Limbah dan Daur Ulang }\end{array}$ & 1,693 & 1,693 & 1,582 & 1,538 & 1,470 & 1,595 \\
\hline Konstruksi & 1,428 & 1,430 & 1,341 & 1,275 & 1,306 & 1,356 \\
\hline $\begin{array}{l}\text { Perdagangan Besar dan Eceran; Reparasi } \\
\text { Mobil dan Sepeda Motor }\end{array}$ & 0,923 & 0,927 & 0,866 & 0,804 & 0,804 & 0,865 \\
\hline Transportasi dan Pergudangan & 2,707 & 2,750 & 2,553 & 2,292 & 2,133 & 2,487 \\
\hline Penyediaan Akomodasi dan Makan Minum & 0,658 & 0,656 & 0,615 & 0,611 & 0,627 & 0,633 \\
\hline Informasi dan Komunikasi & 0,853 & 0,853 & 0,797 & 0,738 & 0,739 & 0,796 \\
\hline Jasa Keuangan dan Asuransi & 0,692 & 0,685 & 0,647 & 0,600 & 0,600 & 0,645 \\
\hline Real Estate & 1,292 & 1,299 & 1,219 & 1,133 & 1,134 & 1,215 \\
\hline Jasa Perusahaan & 0,922 & 0,921 & 0,862 & 0,800 & 0,800 & 0,861 \\
\hline $\begin{array}{l}\text { Administrasi Pemerintahan, Pertahanan dan } \\
\text { Jaminan Sosial Wajib }\end{array}$ & 1,108 & 1,103 & 1,030 & 0,951 & 0,949 & 1,028 \\
\hline Jasa Pendidikan & 1,085 & 1,087 & 1,013 & 0,942 & 0,944 & 1,014 \\
\hline Jasa Kesehatan dan Kegiatan Sosial & 1,376 & 1,373 & 1,283 & 1,186 & 1,190 & 1,281 \\
\hline Jasa lainnya & 1,157 & 1,158 & 1,084 & 1,004 & 1,002 & 1,081 \\
\hline
\end{tabular}

Sumber: Data diolah

Sektor industri pengolahan memiliki nilai LQ sebesar 1,271. Berbagai produk industri pengolahan yang dimiliki Kabupaten Lombok Tengah seperti kain tenun, produk kerajinan dan makanan khas daerah merupakan komoditas penting yang sering dibeli oleh wisatawan.

Sektor penyediaan akomodasi dan makan minum hanya memiliki nilai LQ sebesar 0,633. Angka LQ tersebut menunjukkan sektor tersebut belum menjadi sektor basis di Kabupaten Lombok Tengah. Kemajuan kegiatan pariwisata sangat membutuhkan ketersediaan hotel dan restoran. Oleh karena itu, kesempatan investasi pada sektor tersebut masih terbuka lebar.

\section{Analisis Overlay}

Analisis overlay dilakukan dengan menggabungkan kriteria sektor ekonomi unggulan pada metode shift-share dan kritera sektor ekonomi unggulan pada metode location quotient ( $L Q$ ) yang telah dilakukan sebelumnya. Dengan menggabungkan kedua kriteria tersebut akan diperoleh sektor unggulan yang memenuhi aspek pertumbuhan dan aspek kontribusi terhadap perekonomian Kabupaten Lombok Tengah.

Hasil analisis overlay Kabupaten Lombok Tengah disajikan pada Tabel 3. Yang termasuk sektor unggulan pada analisis overlay adalah sektor-sektor ekonomi pada kategori 1. Adapun sektor ekonomi pada kategori 2 dan kategori 3 termasuk dalam sektor potensial untuk dikembangkan. Berikut ini pembahasan masing-masing kategori dalam analisis overlay. 
Tabel 3.

Hasil Analisis Overlay Kabupaten Lombok Tengah Tahun 2015-2019

\begin{tabular}{|c|c|c|c|}
\hline Sektor Ekonomi & $\begin{array}{c}\text { Sektor } \\
\text { Unggulan Shift } \\
\text { Share }\end{array}$ & $\begin{array}{l}\text { Sektor Unggulan } \\
\text { Location Quotient } \\
\text { (LQ) }\end{array}$ & $\begin{array}{c}\text { Kesimpulan } \\
\text { Analisis } \\
\text { Overlay }\end{array}$ \\
\hline Pertanian, Kehutanan, dan Perikanan & + & + & Kategori 1 \\
\hline Pertambangan dan Penggalian & + & - & Kategori 2 \\
\hline Industri Pengolahan & + & + & Kategori 1 \\
\hline Pengadaan Listrik dan Gas & + & - & Kategori 2 \\
\hline $\begin{array}{l}\text { Pengadaan Air, Pengelolaan Sampah, } \\
\text { Limbah dan Daur Ulang }\end{array}$ & + & + & Kategori 1 \\
\hline Konstruksi & + & + & Kategori 1 \\
\hline $\begin{array}{l}\text { Perdagangan Besar dan Eceran; } \\
\text { Reparasi Mobil dan Sepeda Motor }\end{array}$ & + & - & Kategori 2 \\
\hline Transportasi dan Pergudangan & - & + & Kategori 3 \\
\hline $\begin{array}{l}\text { Penyediaan Akomodasi dan Makan } \\
\text { Minum }\end{array}$ & + & - & Kategori 2 \\
\hline Informasi dan Komunikasi & + & - & Kategori 2 \\
\hline Jasa Keuangan dan Asuransi & + & - & Kategori 2 \\
\hline Real Estate & + & + & Kategori 1 \\
\hline Jasa Perusahaan & + & - & Kategori 2 \\
\hline $\begin{array}{l}\text { Administrasi Pemerintahan, } \\
\text { Pertahanan dan Jaminan Sosial Wajib }\end{array}$ & + & + & Kategori 1 \\
\hline Jasa Pendidikan & + & + & Kategori 1 \\
\hline Jasa Kesehatan dan Kegiatan Sosial & + & + & Kategori 1 \\
\hline Jasa lainnya & + & + & Kategori 2 \\
\hline
\end{tabular}

Keterangan: tanda (+) artinya memenuhi kriteria sebagai sektor unggulan tanda (-) artinya tidak memenuhi kriteria sebagai sektor unggulan

Sumber: Data diolah

\section{Kategori 1}

Sektor - sektor ekonomi pada kategori 1 merupakan sektor yang cukup dominan sehingga harus mendapatkan prioritas dalam pembangunan. Sektor ekonomi yang termasuk kategori ini adalah 1) Sektor Pertanian, Kehutanan, dan Perikanan, 2) Sektor Industri Pengolahan, 3) Sektor Pengadaan Air, Pengelolaan Sampah, Limbah dan Daur Ulang, 4) Sektor Konstruksi, 5) Sektor Real Estate, 6) Sektor Administrasi Pemerintahan, Pertahanan dan Jaminan Sosial Wajib, 7) Sektor Jasa Pendidikan, 8) Sektor Jasa Kesehatan dan Kegiatan Sosial, 9) Sektor Jasa Lainnya.

\section{Kategori 2}

Sektor - sektor ekonomi pada kategori 2 merupakan sektor yang sedang mengalami perkembangan sehingga perlu mendapatkan perhatian untuk ditingkatkan kontribusinya dalam pembentukan PDRB. Sektor ekonomi yang termasuk kategori ini adalah: 1) Sektor Pertambangan dan Penggalian, 2) Sektor Pengadaan Listrik dan Gas, 3) Sektor Perdagangan Besar dan Eceran; Reparasi Mobil dan Sepeda Motor, 4) Sektor Penyediaan Akomodasi dan Makan Minum, 5) Sektor Informasi dan Komunikasi, 6) Sektor Jasa Keuangan dan Asuransi, 7) Sektor Jasa Perusahaan. 


\section{Kategori 3}

Sektor ekonomi pada kategori 3 merupakan sektor ekonomi yang sedang mengalami penurunan sehingga pertumbuhannya perlu terus didorong di masa mendatang. Hanya 1 (satu) sektor ekonomi pada kategori ini yaitu sektor tranportasi dan pergudangan.

Hasil analisis overlay menunjukkan bahwa Kabupaten Lombok Tengah memiliki 9 (sembilan) sektor unggulan yang tersebar baik pada sektor primer, sektor sekunder, maupun sektor tersier. Dengan banyaknya sektor unggulan yang dimiliki, Kabupaten Lombok Tengah tentunya memiliki banyak alternatif yang dapat dipilih sebagai sumber pertumbuhan di masa mendatang.

Sektor pertanian, kehutanan, dan perikanan yang merupakan penyedia bahan baku bagi sektor industuri pengolahan merupakan sektor unggulan. Sektor industri pengolahan yang menciptakan nilai tambah ekonomi sebagai sumber pendapatan juga merupakan sektor unggulan. Sektor konstruksi yang menyerap tenaga kerja yang cukup besar juga merupakan sektor unggulan. Selain itu, sektor jasa-jasa yang menggunakan hasil produksi sektor primer dan sektor sekunder dalam produksinya berperan dalam penciptaan kesempatan kerja.

Dalam kaitannya dengan pengembangan kegiatan pariwisata, dua sektor yang terkait erat dengan kegiatan pariwisata yaitu sektor transportasi dan pergudangan serta sektor penyediaan akomodasi dan makan minum belum termasuk kategori sektor unggulan. Kedua sektor tersebut termasuk sektor yang potensial dan masih perlu ditingkatkan di waktu mendatang. Kehadiran KEK Mandalika yang berpotensi sebagai epicentrum baru pariwisata di Pulau
Lombok diharapkan dapat mendorong kemajuan dua sektor potensial tersebut.

Selain itu, berbagai sektor unggulan yang telah diuraikan sebelumnya dapat memanfaatkan kehadiran KEK Mandalika untuk memperbesar permintaan (demand). Sektor pertanian, kehutan, dan perikanan misalnya, memiliki berbagai komoditas tanaman pangan, sayur-sayuran, buahbuahan, hasil peternakan, dan hasil perikanan. Berbagai produk pertanian tentunya dibutuhkan oleh hotel dan restoran. Aspek kualitas produk tentunya harus menjadi perhatian agar sesuai dengan kriteria yang dibutuhkan oleh kawasan wisata bertaraf internasional.

Kabupaten Lombok Tengah memiliki keuntungan dengan sejumlah alternatif sektor ekonomi unggulan untuk melakukan akselerasi pertumbuhan ekonomi. Tidak semua daerah memiliki keuntungan tersebut. Sebagai contoh, Kabupaten Bulukumba Provinsi Sulawesi Selatan hanya memiliki sektor jasa-jasa (sektor tersier) sebagai sektor unggulan yang memenuhi kriteria location quotient dan shift share (Sapriadi et.al, 2015).

Kabupaten Minahasa Selatan, Provinsi Sulawesi Utara memiliki sektor unggulan pada sektor primer dan sekunder. Sektor unggulan di Kabupaten tersebut yang memenuhi kriteria location quotient dan shift share yaitu sektor pertanian, sektor industri, dan sektor konstruksi (Mangilelang et.al, 2015).

Kabupaten Badung, Provinsi Bali, memiliki 2 (dua) sektor ekonomi yang memiliki pertumbuhan pesat (kriteria shift share) yaitu sektor informasi dan komunikasi; dan sektor administrasi pemerintahan, pertahanan, dan jaminan sosial wajib. Hanya sektor informasi dan komunikasi yang merupakan sektor basis 
dengan LQ>1 dari kedua sektor yang tumbuh pesat tersebut (Wiguna et.al, 2019).

Kondisi daerah dengan sektor unggulan yang mencakup sektor primer, sekunder, dan tersier di Kabupaten Lombok Tengah memiliki kemiripan dengan sektor unggulan yang dimiliki oleh Kabupaten Aceh Barat, Provinsi Aceh (Syahputra et.al, 2015).

\section{SIMPULAN}

Berdasarkan hasil analisis overlay, dari 17 (tujuh belas) sektor ekonomi yang ada, didapatkan bahwa Kabupaten Lombok Tengah memiliki 9 (sembilan) sektor ekonomi unggulan dan 8 (delapan) sektor ekonomi potensial. Dengan kata lain, dalam upaya melakukan akselerasi pertumbuhan ekonomi di Kabupaten Lombok Tengah di masa mendatang, banyak alternatif sektor ekonomi yang dapat dikembangkan.

Sektor ekonomi yang terkait erat dengan kegiatan pariwisata yaitu sektor transportasi dan pergudangan serta sektor penyediaan akomodasi dan makan minum belum termasuk sektor unggulan dan masih termasuk sektor potensial. Oleh karena itu, sektor tersebut masih perlu terus ditingkatkan seiring hadirnya destinasi wisata berkelas internasional di Kabupaten Lombok Tengah.

Sektor unggulan misalnya sektor pertanian, kehutanan, dan perikanan; sektor industri pengolahan; sektor konstruksi; dan sektor jasa-jasa dapat memanfaatkan kehadiran KEK Mandalika untuk meningkatkan permintaan (demand). Besarnya potensi jumlah wisatawan yang datang tentunya akan mendorong perluasan pangsa pasar produk-produk yang dihasilkan Kabupaten Lombok Tengah.

Penelitian selanjutnya dapat mengunakan Analisis Tabel Input Output untuk mengetahui keterkaitan antar sektor ekonomi dan mengetahui dampak dari peningkatan suatu sektor ekonomi terhadap kinerja perekonomian secara umum. Tabel Input Output Kabupaten Lombok Tengah perlu disusun terlebih dahulu untuk melakukan analisis tersebut. Hasil penelitian ini sebagai informasi awal yang menunjukkan besarnya peluang akselerasi pertumbuhan ekonomi Kabupaten Lombok Tengah di waktu mendatang.

\section{DAFTAR PUSTAKA}

Arsyad, L. (2016). Ekonomi Pembangunan Edisi 5. Yogyakarta: UPP STIM YKPN.

Badan Pusat Statistik (BPS) Kabupaten Lombok Tengah. (2020a). Kabupaten Lombok Tengah Dalam Angka 2020. Praya: BPS Kabupaten Lombok Tengah.

Regional Bruto Lombok Tengah Menurut Lapangan Usaha 2015-2019. Praya: BPS Kabupaten Lombok Tengah.

Badan Pusat Statistik (BPS) Provinsi Nusa Tenggara Barat. (2020). Produk Domestik Regional Bruto Nusa Tenggara Barat Menurut Lapangan Usaha 2015-2019. Mataram: BPS Provinsi NTB.

Darmastuti, S., Afrimadona, Kurniawan, A. (2018). Kawasan Ekonomi Khusus (KEK) dan Pembangunan Ekonomi: Sebuah Studi Komparatif Indonesia dan Cina. Jurnal Dinamika Ekonomi Pembangunan, Universitas Pembangunan Nasional Veteran Jakarta. 1(2). 71-81. 
Dewan Nasional Kawasan Ekonomi Khusus Republik Indonesia (DN KEK RI). (n.d.). Profil KEK Pariwisata, KEK Mandalika. Diakses dari https://kek.go.id/kawasan/Mandalika

Indonesia Tourism Development Corporation (ITDC). (2019, Januari 28). DORNA Sports SL dan ITDC Umumkan Partnership untuk membawa acara Balap Motor Paling Populer di Dunia ke Pulau Lombok di Indonesia. Diakses dari https://www.itdc.co.id/press-release/dorna-sports-sl-dan-itdc-umumkan-partnershipuntuk-membawa-acara-balap-motor-paling-populer-di-dunia-ke-pulau-lombok-diindonesia-20191220062044

Islamy, N., (2019). Analisis Sektor Potensial, Dapatkah Pariwisata Menjadi Lokomotif Baru Ekonomi Nusa Tenggara Barat. Journal of Indonesian Tourism, Hospitality, and Recreation. 2 (1). 1-10.

Mangilelang, E.J., Rotinsulu, D., Rompas, W. (2015). Analisis Sektor Unggulan Kabupaten Minahasa Selatan. Jurnal Berkala Ilmiah Efisiensi, Ekonomi Pembangunan, Fakultas Ekonomi dan Bisnis Universitas Sam Ratulangi Manado. 15(4). 193-205.

Narula, R., Zhan, J.X. (2019). Using Special Economic Zones to Facilitate Development: Policy Implications. Transnational Corporations Investment and Development Journal. 26(2). 1-25

Sapriadi, Hasbiullah (2015). Analisis Penentuan Sektor Unggulan Perekonomian Kabupaten Bulukumba. Jurnal Iqtisaduna. 1 (1). 71-86.

Syahputra, H., Hamzah, A., Syahnur, S. (2015). Analisis Sektor Unggulan dan Perubahan Struktur Perekonomian Kabupaten Aceh Barat. Jurnal Ilmu Ekonomi Pascasarjana Universitas Syiah Kuala. 3 (3). 56-68.

Tarigan, R. (2006). Ekonomi Regional Teori dan Aplikasi. Jakarta: Bumi Aksara.

Wiguna, I.M.G.S., Budhi, M.K.S. (2019). Analisis Sektor Unggulan dan Potensi Pertumbuhan Ekonomi di Kabupaten Badung Tahun 2012-2016. Jurnal Ekonomi Pembangunan Universitas Udayana. 8(4). 810-841. 